\title{
Backward conditioning: An artifact of experimental design?
}

\author{
COOPER B. HOLMES and STEPHEN F. DAVIS \\ Emporia State University, Emporia, Kansas 66801
}

\begin{abstract}
Various interpretations of the nature of backward conditioning are briefly considered. After reviewing the three major interpretations of backward conditioning, another possible explanation is offered. It is suggested that backward conditioning may actually be long-trace forward conditioning, with the CS of one pair serving as the CS for the next UCS.
\end{abstract}

The possibility of a backward association in classical conditioning has been studied extensively in the past (e.g., Fitzwater \& Reisman, 1952; Pavlov, 1927; Spooner \& Kellogg, 1947) and continues to be studied in the present (e.g., Hogan \& Zendall, 1977; Wagner \& Terry, 1975). To delineate the exact nature of backward conditioning has proven to be troublesome and controversial. There are three major (interrelated) reasons for this problem. First, the research on backward conditioning has been inconsistent; that is, some researchers can establish backward conditioning, while others cannot. Second, backward conditioning appears to be influenced by whether an appetitive or aversive conditioning paradigm is employed (Razran, 1971). Third, there is no specific agreement as to the experimental design actually constituting backward conditioning. On this third point, for example, Razran (1971) divided the experiments on backward conditioning into three major types (noting, we should add, that his grouping of experiments was tentative). The first type is one in which CS onset occurs after UCS onset and CS termination occurs either with or after UCS termination. The second type of experiment is one in which CS onset occurs with, or after, UCS onset, and CS termination occurs before UCS termination. The third design involves CS onset occurring after UCS termination. As the first two designs involve the simultaneous occurrence of the UCS and CS, it is our opinion that they may not actually constitute backward conditioning. The fact that CS onset occurs after UCS onset does not seem sufficient to nullify the obvious simultaneous presentation of both stimuli. Accordingly, only the third type of design (i.e., in which there is no overlap between the CS and UCS) actually seems to reflect backward conditioning.

The research on backward conditioning and its explanations may be categorized into three groups. One group of researchers has failed to establish backward conditioning at all (e.g., Cason, 1922; Porter, 1938)

Requests for reprints should be sent to Cooper B. Holmes, Department of Psychology, Emporia State University, Emporia, Kansas 66801. and therefore has no reason to offer explanations. The second group of researchers has concluded that backward conditioning is a true associative phenomenon (e.g., Harlow, 1939; Razran, 1956, 1971; Switzer, 1930; Wolfle, 1930). After reviewing the research and explanations on backward conditioning, Razran $(1956,1971)$ concluded that the most likely explanation for backward conditioning was his dominance-contiguity view. This view assumes the UCS to be considerably stronger than the CS, but not so strong as to preclude the subject from attending to the CS. In this situation, Razran feels that a contiguity or association between the dominant UCS and the subsequent CS may be established.

The third group of researchers agrees that what has been called backward conditioning may be established; however, this group feels the phenomenon is the result of variables other than the backward association of the UCS and CS (e.g., Osgood, 1953; Wickens \& Wickens, 1940). Two of the most popular explanations of what appears to be backward conditioning will be presented here. Such respected investigators as Grant (1943), Harris (1941), Osgood, (1953), Underwood (1949), and Wickens and Wickens (1940) believe "backward conditioning" to be nothing more than pseudoconditioning (because of the usually strong UCS employed in backward conditioning experiments). The second major explanation suggests that the CS serves as a signal for UCS termination (e.g., Barlow, 1956; Moscovitch \& LoLordo, 1968). For example, Moscovitch and LoLordo (1968), using shock as the UCS, concluded that the CS acted as a signal for a period of safety (CS presentation was followed by the intertrial interval, during which, of course, no shock was presented).

None of the previous explanations of backward conditioning considered another alternative: that backward conditioning is nothing more than long-trace forward conditioning, with the CS of one UCS-CS pair serving as the CS for the next UCS. A diagram would clarify this point.

It may be seen in Figure 1 that, after the first pairing of the UCS and CS, the conditions for long-trace conditioning are established (i.e., the CS precedes and terminates before the presentation of the UCS, with at 
TIME

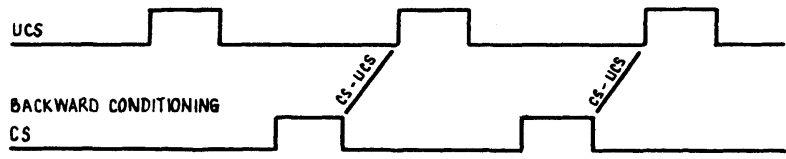

LONG TRACE CONDITIONING

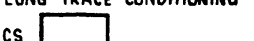

Figure 1. Temporal relationship between CS and UCS in backward and trace conditioning.

least several seconds between the two stimuli). While it would be possible to have short-trace conditions in backward conditioning, long-trace conditioning is suggested here because in backward conditioning the intertrial interval (i.e., our CS-UCS interval) is typically several seconds to several minutes in duration. It is suggested, then, that, actually, a forward CR is being established, not a backward one. In support of this interpretation, it should be noted that long-trace CRs are difficult to establish, just as backward CRs are difficult to establish.

The interpretation we suggest would lead to the expectation that the shorter the intertrial interval in backward conditioning, the greater the probability of establishing a CR. That is, when the intertrial interval is shorter, the CS from one pair is temporally closer to the UCS of the next pair, and the chance of establishing a CR is increased. An extreme example of this point would be to present the UCS-CS pairs with a .5 -sec intertrial interval. (This would lead to short-trace conditioning under optimal conditions.)

Given that we are proposing an alternative interpretation of backward conditioning, it seems requisite to comment on how our view relates to the established data. An analysis of the data on backward conditioning was conducted by the present authors in order to examine whether the length of the intertrial interval is related to establishing (or failing to establish) a backward CR. However, it is difficult to draw any firm conclusions because the intertrial intervals were typically reported as means or as ranges of time intervals, thus yielding data too gross for the necessary analysis.

On the other hand, Razran (1956) concluded that the empirical data he reviewed was "against any assumption that backward CR's are merely forward CR's to traces or aftereffects of CS's"' (p. 67). He based this conclusion on "the fact that (a) with food as the US backward conditioning is more effective with $15 \mathrm{sec}$. US-CS delays than with shorter intervals and that (b) with shock as the US it is effective only when the CS is applied after the shock has ceased" (Razran, 1956, p. 67). It is interesting to note that Razran's conclusions were based on four Russian experiments, none of which employed more than two subjects (dogs). More importantly, however, Razran's suggestions may lend some support to our view. The fact that backward conditioning is more effective with longer UCS-CS intratrial intervals would theoretically allow a clearer grouping of the CS of one backward conditioning trial with the UCS of the next. Also, Razran noted that the best backward conditioning occurred when there is no intratrial overlap between the UCS and the CS, and this, of course, defines trace conditioning.

Lacking empirical support, the interpretation of backward conditioning advocated in this article, as appealing and logical as it may be, must certainly be viewed as tentative at best. The intent of the present paper was not to advocate one particular interpretation as absolutely correct, but rather, to propose what appears to us to be a viable alternative to the extant considerations. The present analysis does suggest, however, certain experiments that might shed additional light upon the nature of the phenomenon in question. For example, various manipulations (either independent or simultaneous) of inter- and intratrial intervals would appear warranted. Further, it may be found that such manipulations will produce different results in appetitive, as compared with aversive, conditioning situations.

\section{REFERENCES}

Barlow, J. A. Secondary motivation through classical conditioning: A reconsideration of the nature of backward conditioning. Psychological Review, 1956, 63, 406-408.

CAson, H. The conditioned eyelid reaction. Journal of Experimental Psychology, 1922, 5, 153-196.

Fitzwater, M. E., \& Reisman, M. N. Comparison of forward, simultaneous, backward, and pseudo-conditioning. Journal of Experimental Psychology, 1952, 44, 211-214.

Grant, D. A. The pseudo-conditioned eyelid response. Journal of Experimental Psychology, 1943, 32, 139-149.

HaRLow, H. F. Forward conditioning, backward conditioning, and pseudo-conditioning in the goldfish. Journal of Genetic Psychology, 1939, 55, 49-58.

HARRIS, J. D. Forward conditioning, backward conditioning, and pseudo-conditioning and adaptation to the conditioned stimulus. Journal of Experimental Psychology, 1941, 28, 491-502.

Hog AN, D. E., \& ZENDALl, T. R. Backward associations in the pigeon. American Journal of Psychology, 1977, 90, 3-15.

Moscovitch, A., \& LoLondo, V. M. Role of safety in the Pavlovian backward fear conditioning procedure. Journal of Comparative and Physiological Psychology, 1968, 66, 673-678.

Osgood, C. E. Method and theory in experimental psychology. New York: Oxford University Press, 1953.

Pavlov, I. P. [Conditioned reflexes] (G. V. Anrep, trans.). London: Oxford University Press, 1927.

Porter, J. M. Backward conditioning of the eyelid response. Journal of Experimental Psychology, 1938, 23, 403-410.

Razran, G. Backward conditioning. Psychological Bulletin, 1956, 53, 55-69.

Razran, G. Mind in evolution. Boston: Houghton Mifflin, 1971.

Spooner, A., \& Kellogg, W. N. The backward conditioning curve. American Journal of Psychology, 1947, 60, 321-334.

Switzer, S. A. Backward conditioning of the lid reflex. Journal of Experimental Psychology, 1930, 13, 76-97.

UNDERWOOD, B. J. Experimental psychology. New York: Appleton-Century-Crofts, 1949.

WAGNer, A. R., \& Terry, W. S. Backward conditioning to a CS following an expected versus a surprising UCS. Animal Learning \& Behavior, 1975, 3, 370-374.

Wickens, D. D., \& WiCKENS, C. D. Study of conditioning in the neonates. Journal of Experimental Psychology, 1940, 26, 94-102.

Wolfle, H. M. Time factors in conditioning finger withdrawal. Journal of General Psychology, 1930, 4, 372-378.

(Received for publication September 7, 1979.) 